\title{
NILAI SENSITIVITAS, SPESIFISITAS, POSITIVE PREDICTIVE VALUE DAN NEGATIVE PREDICTIVE VALUE SPHYGMOMANOMETER DIGITAL PADA SKRINING HIPERTENSI
}

\author{
Ravenalla Abdurrahman Al Hakim Sampurna Putra $S^{I}$ \\ Program Studi Pendidikan Dokter, Fakultas Kedokteran, Universitas Palangka Raya \\ Email: raven.abdurahman@med.upr.ac.id
}

\begin{abstract}
ABSTRAK
Berdasarkan data hipertensi terlihat bahwa hipertensi sendiri masih merupakan momok bagi kesehatan penduduk Indonesia. Pada tahun 2012 data PTM menunjukkan terdapat 554.771 kasus Hipertensi Esensial di Jawa Tengah. Data PTM Kabupaten Purbalingga khususnya untuk tahun 2012 menunjukkan bahwa kasus Hipertensi Esensial merupakan PTM dengan kasus terbanyak dengan total 7.440 kasus dan Hipertensi lainnya 3.616 kasus. Penelitian ini bertujuan untuk melakukan deteksi dini penderita hipertensi di Kecamatan Purbalingga Kabupaten Purbalingga, mengetahui sensitivitas, spesifisitas, PPV dan NPV dari sphygmomanometer digital yang digunakan. Penelitian ini merupakan uji diagnostic pada skrining hipertensi. Sasaran skrining adalah orang yang tinggal di wilayah kerja Puskesmas Purbalingga dengan umur di atas 30 tahun. Dasar perhitungan jumlah sampel mengacu kepada besar rumus besar sampel dari Burderer. Alat yang digunakan adalah sphygmomanometer digital serta sphygmomanometer air raksa (sebagai gold standart) sesuai dengan prosedur yang sudah ditentukan. Dari Hasil skrining menggunakan tensimeter air raksa didapatkan 53 responden menderita hipertensi, menggunakan tensimeter digital didapatkan 48 responden menderita hipertensi. Hasil skrining hipertensi di Puskesmas Purbalingga menunjukkan bahwa tensimeter digital yang digunakan memiliki sensitifitas 90,6\%, spesifitas 100\%,PPV 100\% dan NPV 87,2\%. Hal ini menunjukkan hasil yang tidak terlalu berbeda dibandingkan sphygmomanometer air raksa yang merupakan gold standart untuk pengukuran hipertensi.
\end{abstract}

Kata Kunci: Sensitivitas, Spesifisitas, PPV, NPV, Hipertensi

\begin{abstract}
Based on data shows, that hypertension itself is still a scourge for the health of the Indonesian population. Central Java in 2012 PTM data showed that there were 554,771 cases of essential hypertension. This study aims to conduct early detection of hypertension sufferers in Purbalingga District, Purbalingga Regency, to determine the sensitivity, specificity, PPV and NPV of a sphygmomanometer digital. This study is a diagnostic test for hypertension screening. The target of screening is people who live in the working area of Purbalingga Health Center and are over 30 years old. The basis for specificity is used because it is closely related to Positive Predictive Value (PPV) where the greater the specificity, the greater the PPV value and the PPV value illustrating the prevalence of disease. The basis for calculating the number of samples refers to the sample size formula from Burderer. The tool used is a sphygmomanometer digital as well as a sphygmomanometer mercury (as the gold standard) according to a predetermined procedure. From the results of screening using mercury tensimeter, it was found that 53 respondents had hypertension, using a digital tensimeter, it was found that 48 respondents had hypertension. The results of hypertension screening at Purbalingga Health Center showed that the digital tensimeter used had a sensitivity of $90.6 \%$, a specificity of $100 \%, 100 \%$ PPV and $87.2 \%$ NPV. This shows the results are not too different from sphygmomanometer the mercurywhich is the gold standard for measuring hypertension.
\end{abstract}

Key Words: Sensitivity, Specificity, PPV, NPV, Hypertention 


\section{Pendahuluan}

Hipertensi atau penyakit tekanan darah tinggi merupakan salah satu penyebab utama kematian dan cacat di negara berkembang. Di seluruh dunia, tekanan darah tinggi menyebabkan 7,5 juta kematian atau sekitar $12.8 \%$ dari total kematian. Prevalensi tekanan darah tinggi tertinggi terdapat pada kawasan Afrika (46\%) sedangkan untuk kawasan Asia Tenggara 36\%. Prevalensi terus meningkat pada negara kawasan Asia, India mengalami kenaikan dari 5\% penderita pada tahun 1960 -an menjadi $12 \%$ pada 1990 an dan menjadi lebih dari $30 \%$ pada tahun 2008. Indonesia, persentase penduduk dewasa dengan tekanan darah tinggi meningkat dari 8\% tahun 1995 menjadi 32\% pada tahun $2008 .^{1}$

Jumlah penderita hipertensi di seluruh dunia terus meningkat. Di India jumlah hipertensi mencapai 60,4 juta orang pada tahun 2002 dan diperkirakan 107,3 juta orang pada tahun 2025. Di Cina sebanyak 98,5 juta orang mengalami hipertensi dan diperkirakan menjadi 151,7 juta orang pada tahun 2025. Di Asia sendiri tercatat 38,4 juta penderita hipertensi pada tahun 2000 dan diprediksi akan menjadi 67,4 juta pada tahun $2005 .^{2}$

Hipertensi merupakan salah satu penyakit tidak menular (PTM) yang menjadi suatu masalah kesehatan serius. Hipertensi apabila tidak terkontrol kedepannya dapat menyebabkan stroke, serangan jantung, gagal ginjal serta kebutaan. Gaya hidup yang tidak sehat, modernisasi, kurang aktifitas fisik serta ketidak stabilan emosional dapat memicu timbulnya hipertensi. PTM dapat dicegah dengan mengendalikan faktor risiko PTM tersebut. Dalam proses pencegahan dan penanggulangan PTM diperlukan kombinasi upaya inisiatif pemeliharaan kesehatan mandiri oleh petugas kesehatan dan individu yang bersangkutan. Tantangan yang dihadapi adalah pengembangan suatu sistem pelayanan yang dapat mendukung upaya pemeliharaan kesehatan mandiri, dengan melakukan redefinisi peran dan fungsi seluruh sarana pelayanan kesehatan, untuk menghubungkan pelayanan medis dengan pendekatan promosi dan pencegahannya. World Health Organization (WHO) merekomendasikan penanggulangan PTM melalui tiga komponen, yaitu surveilans faktor risiko, promosi kesehatan dan pencegahan serta inovasi dan reformasi manajemen pelayanan kesehatan yang diterapkan secara terpadu dan menyeluruh. Departemen Kesehatan RI telah merujuk rekomendasi ketiga komponen WHO tersebut dengan menyusun kebijakan dan strategi pencegahan dan penanggulangan PTM secara komprehensif. 1,3

Jawa Tengah pada tahun 2012 data PTM menunjukkan terdapat 554.771 kasus Hipertensi Esensial yang merupakan kasus PTM tertinggi. Data PTM Kabupaten Purbalingga khususnya untuk tahun 2012 menunjukkan bahwa kasus Hipertensi Esensial merupakan PTM dengan kasus terbanyak dengan total 7.440 kasus dan Hipertensi lainnya 3.616 kasus., ${ }^{4,5}$

Data menunjukkan bahwa hipertensi sendiri masih merupakan momok bagi kesehatan penduduk Indonesia terutama di Jawa Tengah. Purbalingga sendiri kasus hipertensi esensial merupakan PTM dengan kasus tertinggi, untuk itu perlu dilakukan skrining hipertensi agar penyakit ini dapat dideteksi dini sehingga kedepannya tidak menyebabkan penyakit lanjutan seperti yang dijelaskan di atas. 
Gold standart dalam skrining hipertensi atau pengukuran tekanan darah adalah spygmomanometer air raksa. Alat skrining hipertensi yang akan digunakan adalah sphygmomanometer digital yang bekerja otomatis. Tekanan darah akan tampil di layar setelah sphygmomanometer digital selesai mengukur tekanan darah. Pengukur tekanan darah digital ini beroperasi dengan menggunakan tenaga baterai, hasil pengukurannya dapat langsung terlihat pada layar monitor yang memunculkan angka pengukuran tekanan darah. Penggunaan sphygmomanometer digital dikarenakan hasil pengukurannya yang lebih presisi serta mengingat Spygmomanometer air raksa merupakan alat kesehatan yang mengandung raksa yang diketahui berbahaya bagi kesehatan. Jadi penggunaan sphygmomanometer digital dirasa lebih aman serta lebih mudah digunakan karena dapat dilakukan oleh diri sendiri. ${ }^{6}$

Penelitian ini bertujuan untuk mengetahui sensitivitas dan spesifisitas dari sphygmomanometer digital dalam menegakkan diagnosis hipertensi, Mengetahui nilai duga positif/Positive Predictive Value (PPV) dan nilai duga negatif/Negative Predictive Value (NPV) dari sphygmomanometer digital dalam menegakkan diagnosis hipertensi dan Mengetahui gambaran penderita hipertensi di Kecamatan Purbalingga Kabupaten Purbalingga.

\section{Metode Penelitian}

Penelitian ini menggunakan uji diagnostik pada skrining hipertensi. Sasaran skrining adalah orang yang tinggal di wilayah kerja Puskesmas Purbalingga dengan umur di atas 30 tahun. Dasar perhitungan jumlah sampel mengacu kepada besar rumus besar sampel dari Burderer dan didapatkan hasil sebanyak 87 responden.

Uji Diagnostik menggunakan sphygmomanometer digital dengan merk "X". Alat ini adalah alat pemeriksa tekanan darah secara digital menampilkan tekanan darah sistolik dan diastolik pasien/responden. Alat ini sangat mudah dalam penggunaanya dan tidak membutuhkan keahlian/keterampilan khusus. Baku emas dalam skrining ini menggunakan Sphygmomanometer Air Raksa. Baku emas ini dipilih karena Sphygmomanometer air raksa memiliki akurasi yang paling baik dibandingkan Sphygmomanometer lainnya. ${ }^{7}$ Dalam menilai validitas pengukuran suatu uji skrining, hasil pengukuran uji tersebut dibandingkan dengan suatu gold standart dengan menyusun tabel $2 \times 2$. Uji validitas yang dilakukan adalah Sensitivitas, Spesifisitas, Positive Predictive Value dan Negative Predictive Value.

\section{Hasil}

Analisis univariat yang dilakukan pada peneltian ini dilakukan untuk melihat distribusi umur, jenis kelamin dan hasil pemeriksaan hipertensi, seperti yang disajikan pada tabel-tabel berikut. 
Tabel 1. Karakteristik responden skrining hipertensi

\begin{tabular}{ccc}
\hline Karakteristik & $\mathrm{n}$ & $\%$ \\
Umur & & \\
30-40 tahun & 11 & $12,64 \%$ \\
41-50 tahun & 27 & $31,03 \%$ \\
51-60 tahun & 26 & $29,89 \%$ \\
$\geq 61$ tahun & 23 & $26,44 \%$ \\
Jenis kelamin & & \\
Laki-laki & 27 & $31,03 \%$ \\
Perempuan & 60 & $68,97 \%$ \\
\hline
\end{tabular}

Tabel 2. Distribusi penderita hipertensi menggunakan sphygmomanometer air raksa menurut kelompok umur

\begin{tabular}{clll}
\hline \multirow{2}{*}{$\begin{array}{c}\text { Kelompok } \\
\text { umur }\end{array}$} & \multicolumn{2}{c}{ Status hipertensi } & \multirow{2}{*}{ Jumlah } \\
\cline { 2 - 3 } $30-40$ & 3 & 8 & $11(100 \%)$ \\
& $(27,27 \%)$ & $(72,73 \%)$ & \\
$41-50$ & 18 & 9 & $27(100 \%)$ \\
& $(66,67 \%)$ & $(33,33 \%)$ & \\
$51-60$ & 19 & 7 & $26(100 \%)$ \\
& $(73,08 \%)$ & $(26,92 \%)$ & \\
\multirow{2}{*}{$\geq 61$} & 13 & 10 & $23(100 \%)$ \\
& $(56,52 \%)$ & $(43,48 \%)$ & \\
\hline Jumlah & 53 & 34 & $87(100 \%)$ \\
\hline
\end{tabular}

Tabel. 3 Distribusi penderita hipertensi menggunakan sphygmomanometer air raksa menurut jenis kelamin

\begin{tabular}{|c|c|c|c|}
\hline \multirow{2}{*}{$\begin{array}{c}\text { Jenis } \\
\text { kelamin }\end{array}$} & \multicolumn{2}{|c|}{ Status hipertensi } & \multirow{2}{*}{ Jumlah } \\
\hline & ya & tidak & \\
\hline Laki-laki & $\begin{array}{l}16 \\
(59,26 \%)\end{array}$ & $\begin{array}{l}11 \\
(40,74 \%)\end{array}$ & $27(100 \%)$ \\
\hline Perempuan & $\begin{array}{l}37 \\
(61,67 \%)\end{array}$ & $\begin{array}{l}23 \\
(38,33 \%)\end{array}$ & $60(100 \%)$ \\
\hline Jumlah & $\begin{array}{l}53 \\
(60,92 \%)\end{array}$ & $\begin{array}{l}34 \\
(39,08 \%)\end{array}$ & $87(100 \%)$ \\
\hline
\end{tabular}

Tabel 4. Distribusi penderita hipertensi menggunakan sphygmomanometer digital menurut kelompok umur

\begin{tabular}{clll}
\hline \multirow{2}{*}{$\begin{array}{c}\text { Kelompok } \\
\text { umur }\end{array}$} & \multicolumn{2}{c}{ Status hipertensi } & Jumlah \\
\cline { 2 - 3 } & \multicolumn{2}{c}{ ya } & \multicolumn{2}{c}{ tidak } & \\
\hline $30-40$ & 2 & 9 & $11(100 \%)$ \\
\multirow{2}{*}{$41-50$} & $(18,18 \%)$ & $(81,82 \%)$ & \\
& 16 & 11 & $27(100 \%)$ \\
$51-60$ & $(59,26 \%)$ & $(40,74 \%)$ & \\
& 17 & 9 & $26(100 \%)$ \\
$\geq 61$ & $(65,38 \%)$ & $(34,62 \%)$ & \\
& 13 & 10 & $23(100 \%)$ \\
& $(56,52 \%)$ & $(43,48 \%)$ & \\
\hline Jumlah & 48 & 39 & \\
& $(55,17 \%)$ & $(44,83 \%)$ & \\
\hline
\end{tabular}


Tabel 5. Distribusi penderita hipertensi menggunakan sphygmomanometer digital menurut jenis kelamin

\begin{tabular}{|c|c|c|c|}
\hline \multirow{2}{*}{$\begin{array}{c}\text { Jenis } \\
\text { kelamin }\end{array}$} & \multicolumn{2}{|c|}{ Status hipertensi } & \multirow{2}{*}{ Jumlah } \\
\hline & Ya & tidak & \\
\hline \multirow[t]{2}{*}{ Laki-laki } & 15 & 12 & $27(100 \%)$ \\
\hline & $(55,56 \%)$ & $(44,44 \%)$ & \\
\hline \multirow[t]{2}{*}{ Perempuan } & 33 & 27 & $60(100 \%)$ \\
\hline & $(55,00 \%)$ & $(45,00 \%)$ & \\
\hline \multirow[t]{2}{*}{ Jumlah } & 48 & 39 & $87(100 \%)$ \\
\hline & $(55,17 \%)$ & $(44,83 \%)$ & \\
\hline
\end{tabular}

Berdasarkan tabel 1 di atas responden dengan kelompok umur 41-50 tahun $(31,03 \%)$ dan berjenis kelamin perempuan $(68,97 \%)$ paling banyak menjadi responden dalam skrining hipertensi ini. Mengingat pelaksanaan dilakukan di puskesmas yang merupakan tempat pelayanan orang sakit, kemungkinan kelompok umur dan jenis kelamin responden yang datang tidak mempengaruhi karena mereka datang memang karena memiliki keluhan. Kemudian terlihat juga pada tabel-tabel di atas, bahwa distribusi penderita hipertensi terbanyak menggunakan sphygmomanometer air raksa adalah kelompok umur 51-60 $(73,08 \%)$ tahun dan berdasarkan jenis kelamin adalah jenis kelamin perempuan $(61,67 \%)$. Dan distribusi penderita hipertensi terbanyak menggunakan sphygmomanometer digital adalah kelompok umur 51-60 $(65,38 \%)$ tahun dan berdasarkan jenis kelamin adalah jenis kelamin perempuan $(55,00 \%)$.

\section{Pembahasan}

Hipertensi erat kaitannya dengan umur, semakin tua seseorang semakin besar risiko terserang hipertensi. Umur lebih dari 40 tahun mempunyai risiko terkena hipertensi. Dengan bertambahnya umur, risiko terkena hipertensi lebih besar sehingga prevalensi hipertensi dikalangan usia lanjut cukup tinggi yaitu sekitar $40 \%$ dengan kematian sekitar $50 \%$ diatas umur 60 tahun. Arteri kehilangan elastisitasnya atau kelenturannya dan tekanan darah seiring bertambahnya usia, kebanyakan orang hipertensinya meningkat ketika berumur lima puluhan dan enam puluhan. Sedangkan menurut jenis kelamin, perempuan merupakan penderita hipertensi terbanyak, hal ini sama seperti penelitian Bustan yang menunjukkan bahwa jenis kelamin perempuan lebih mudah terkena hipertensi karena terdapatnya hormon estrogen pada perempuan. Pada perempuan hal ini juga memiliki kemungkinan disebabkan oleh hal lain seperti tingkat aktivitas fisik dan juga pola mengkonsumsi makanan. hipertensi adalah kondisi di mana seseorang mengalami peningkatan tekanan darah di atas normal yang ditunjukkan oleh angka sistolik dan diastolik. Hipertensi berupa peningkatan yang bersifat konstan pada saat istirahat dimana tekanan sistolik antara $140-160$ $\mathrm{mmHg}$ dan tekanan diastolik $90-95 \mathrm{mmHg}$. Jadi secara operasional, seseorang dikatakan sebagai individu dengan hipertensi jika tekanan darah sistolik lebih besar dari 140 $\mathrm{mmHg}$ dan atau diastolik lebih besar dari 90 mmHg. ${ }^{8,9}$

Melihat dari hasil skrining hipertensi yang telah dilakukan dengan menggunakan tensimeter digital dan air raksa, terlihat bahwa sensitivitas dan spesivisitas tensimeter digital yang digunakan termasuk tinggi karena mencapai nilai sensitifitas $90,6 \%$ dan spesivisitas $100 \%$, hal ini menunjukkan bahwa tensimeter digital mampu mendeteksi mereka yang benar-benar hipertensi sebesar $90,6 \%$ dan dengan nilai spesivisitas $100 \%$ 
tensimeter digital memiliki kemampuan mendeteksi mereka yang benar-benar tidak hipertensi sebesar 100\%. PPV tensimeter digital mencapai $100 \%$ yang berarti mereka dengan hasil tes positif menggunakan tensimeter digital $100 \%$ benar-benar Tabel 6. Tabel 2x2 Pemeriksaan Skrining Tensimeter Digital dan tensimeter air raksa sphygmomanometer

\begin{tabular}{lllll}
\multicolumn{2}{c}{ Alat pemeriksa } & \multicolumn{2}{c}{ digital } & Jumlah \\
\cline { 2 - 3 } & & + & - & \\
\hline sphygmom & + & 48 & 5 & 53 \\
anometer & - & 0 & 34 & 34 \\
air raksa & & & &
\end{tabular}

48
39 87 hipertensi dan dengan NPV sebesar 87,2\% berarti mereka dengan hasil tes negatif menggunakan tensimeter digital kemungkinan $87,2 \%$ benar-benar tidak hipertensi.

dalam mendeteksi hipertensi termasuk tinggi yaitu 90,6\% bila Dibandingkan dengan tensimeter air raksa yang merupakan gold standart untuk mengukur hipertensi, angka ini termaşuk tinggi (batas tokpansi untuk sensitifitas $>70 \%$ ). Penggunaan tensimeter digital maupun tensimeter air raksa untuk skrining hipertensi harus diperhatikan dalam hal pengkalibrasian, secara berkala 9 s. sphygmomanometer baik raksa maupun digital harus dikalibrasi untuk menjaga keakuratannya dalam pengukuran. ${ }^{10,11,12}$

Nilai sensitivitas dan spesifisitas tersebut dapat digunakan karena masih dalam batas toleransi (>70) dan untuk masalah kesehatan penyakit tidak menular dengan prevalensi yang sangat besar dan beban penyakit yang terlalu besar seperti hipertensi. ${ }^{13}$ (hen)

Tabel 7. Tabel Hasil Perhitungan Sensitivitas (Sn), Spesifisitas (Sp), PPV dan NPV

\begin{tabular}{l|l|l|l}
\hline Sn & Sp & PPV & NPV \\
\hline $90,6 \%$ & $100 \%$ & $100 \%$ & $87,2 \%$ \\
\hline
\end{tabular}

Berdasarkan hasil pelaksanaan skrining di atas diperoleh hasil responden yang benarbenar sakit (true positive) ada 48 orang, responden yang sakit tapi hasil tes positif (false positif) ada 5 orang, responden yang tidak sakit tapi hasil tes positif (false negative) ada 0 orang, dan responden yang tidak sakit dan hasil tes negatif (true negative) ada 49 orang.

\section{Penggunaan sphygmomanometer} digital juga dapat dikatakan lebih aman dibandingkan menggunakan tensimeter air raksa karena tidak mengandung unsur mercury, selain itu juga pengoprasian alatnya lebih mudah dan terlebih lagi melalui skrining ini terlihat bahwa sensitifitasnya
Berdasarkan penelitian serupa yang dilakukan oleh Ostchega (2012) bahwa tensimeter digital yang digunakan juga memiliki nilai sensitifitas, spesifisitas di atas $70 \%$ yaitu sebesar 70,28\% dan $97,38 \%$ dibandingkan dengan gold standart untuk mendeteksi hipertensi. (ostchega) Penelitian lainnya juga menunjukkan bahwa tensimeter digital memiliki sensitivitas $93 \%$, spesifisitas 95\%, PPV 96\%, dan NPV 93\%. (cheng) Namun, berdasarkan penelitian Shahbabu (2016), dikatakan bahwa tensimeter digital masih memiliki angka spesifitas dibawah angka spesifitas tensimeter air raksa. Meskipun ada perbedaan hasil pengukuran antara tensimeter digital dengan tensimeter air raksa, namun pada dasarnya dalam pelaksanaan pemerikasaan, keduanya tetap 
memberikan hasil yang signifikan. ${ }^{14,15,16,17}$ (A.Court)

Pelaksanaan tes skrining tidak selalu dimaksudkan untuk langsung mendiagnosa suatu penyakit namun lebih untuk menjaring orang-orang yang tampak sehat namun mungkin sakit tetapi belum menampakkan gejala, dengan melakukan skrining diharapkan dapat mendeteksi penyakit secara dini, mendiagnosisnya dan dapat menanganinya dengan memberikan pengobatan atau tindakan lainnya. Dalam pelaksanaannya mendeteksi ada tidaknya suatu penyakit pada seseorang yang tampak sehat, skrining sangat bergantung pada sensitivitas dan spesivisitas alat skrining yang digunakan. ${ }^{18,19}$

Berdasarkan hasil penelitian skrining yang dilakukan di Puskesmas Purbalingga terlihat bahwa masih perlu dilakukan skrining hipertensi kedepannya melihat masih banyaknya pasien dengan hipertensi yang datang ke puskesmas, namun tidak terbatas hanya dilakukan di puskesmas tetapi dapat dilakukan di luar kegiatan puskesmas.

Terdapat faktor-faktor yang mungkin mempengaruhi terhadap pelaksanaan skrining hipertensi ini seperti jumlah responden dalam pelaksanaan skrining ini hanya 87 responden yang merupakan pengunjung puskesmas Purbalingga pada tanggal 25-26 januari 2014, ini tentu belum mencerminkan distribusi populasi secara menyeluruh untk wilayah kecamatan Purbalingga sendiri untuk mengetahui masyarakat yang berpotensi menderita hipertensi dan banyaknya jumlah pengunjung yang mengantri untuk mendapatkan pelayanan tentunya membuat pelaksanaan skrining hipertensi yang memerlukan dua kali pengukuran untuk masing-masing alat ukur tidak dapat dilakukan dengan maksimal karena dapat membuat jumlah antrian semakin panjang karena skrining dilakukan bersamaan pada saat pemeriksaan pasien. Selain itu perlu diperhatikan faktor-faktor risiko dari hipertensi itu sendiri seperti usia, Pendidikan, pekerjaan, riwayat keluarga, status gizi dan juga riwayat keluarga. ${ }^{20,21}$

Uji diagnostik ini dilakukan untuk membantu dalam penentuan diagnosis pada pasien di mana masih terdapat ketidakpastian dalam penegakkannya. Di mana dalam pelaksanaannya uji diagnostik harus menentukan sensitivitas, spesifisitas, nilai prediktif positif dan juga nilai prediksi negatif dari kedua tensimeter yang diuji. Kedepannya perlu dilakukan kembali penelitian serupa dengan menggunakan sphygmomanometer digital terbaru mengingat perkembangan teknologi kesehatan semakin maju kedepannya sehingga akan mempengaruhi hasil dari alat kesehatan itu sendiri

\section{Kesimpulan}

Berdasarkan hasil skrining hipertensi yang dilakukan, ditemukan bahwa distribusi penderita hipertensi terbanyak menggunakan sphygmomanometer air raksa adalah kelompok umur 51-60 (73,08\%) tahun dan berdasarkan jenis kelamin adalah jenis kelamin perempuan $(61,67 \%)$. Dan distribusi penderita hipertensi terbanyak menggunakan sphygmomanometer digital adalah kelompok umur 51-60 (65,38\%) tahun dan berdasarkan jenis kelamin adalah jenis kelamin perempuan $(55,00 \%)$. Uji diagnostik yang dilakukan memperlihatkan bahwa sphygmomanometer digital yang digunakan menunjukkan hasil yang tidak terlalu berbeda dibandingkan sphygmomanometer air raksa yang merupakan gold standart untuk pengukuran hipertensi dan sphygmomanometer digital lebih aman dalam penggunaannya karena tidak mengandung merkuri seperti sphygmomanometer air raksa. 


\section{Daftar Pustaka}

1. WHO. World Health Day 2013.

2. Lancet. Prevalence of Primary Hyperaldosteronism in Resistant Hypertension: A Retrospective Observational Study. Pub Med Journal 372, 2022. 2008

3. Depkes RI. Pedoman Pengendalian Penyakit Jantung Dan Pembuluh Darah . Departemen Kesehatan Republik Indonesia. Jakarta. 2013

4. Dinas Kesehatan Provinsi Jawa Tengah. Buku Profil Dinas Kesehatan Provinsi Jawa Tengah 2011. 2012

5. Riset Kesehatan Dasar. Departemen Kesehatan Republik Indonesia, Jakarta. 2013

6. Fuentes, R dan Banuelos, M.A. Digital Blood Pressure Monitor. Laboratorio de Electronica, Centro de Ciencias Aplicadas y Desarrollo Tecnologico UNAM. 2: 224229. 2003

7. JNC. Prevention, Detection, Evaluation and Treatment of High Blood Pressure. U.S Department of Health And Human Services (The Joint National Committee on Detection, Evaluation and Treatment Of High Blood Pressure). 2004

8. Sugiharto, A. Faktor-Faktor Risiko Hipertensi Grade II Pada Masyarakat. Tesis, Universitas Diponegoro. Semarang. 2007.

9. Lidya, H.A. Studi Prevalensi Dan Determinan Hipertensi Di Provinsi Kepulauan Bangka Belitung. Universitas Indonesia. Jakarta. 2011

10. Beaglehole. Basic epidemiology $2^{\text {nd }}$ edition. Geneva. WHO. 2006
11. Budiarto. E dan Anggraini, D. (2002) Pengantar Epidemiologi. Jakarta: Penerbit buku Kedokteran EGC. 2006

12. Bustan, M.N. Epidemiologi Penyakit Tidak Menular. Jakarta: Rineka Cipta 29-38. 1997

13. hen, Z., Wang, X., Wang, Z., Zhang, L., Hao, G., Dong, Y., Zhu, M., Gao, R. Assessing the Validity of Oscillometric Device for Blood Pressure Measurement in a Large Population-based Epidemiologic study. Journal of the American Society of Hypertension, 11(11). 2017

14. Ostchega,Y., Zhang, G., Sorlie, P., Hughes, J., Debra S., Nwankwo, T., Yoon, S. Blood Pressure Randomized Methodology Study Comparing Automatic Oscillometric and Mercury Sphygmomanometer Devices: National Health and Nutrition Examination Survey, 2009-2010. National Health Statistics Reports, Number 59, October 5. 2012

15. Cheng, H.-M., Sung, S.-H., Chuang, S.Y., Pearson, A., Tufanaru, C., White, S., $Y u, \quad W C$., Chen, C.-H. Diagnostic Performance of a Stand-Alone Central Blood Pressure Monitor: Application of Central Blood Pressure in the Diagnosis of High Blood Pressure. American Journal of Hypertension, 27(3), 382-391. 2014

16. Shahbabu, B., Dasgupta, A., Sarkar, K., \& Sahoo, S. K. Which is More Accurate in Measuring the Blood Pressure? A Digital or an Aneroid Sphygmomanometer. Journal of Clinical and Diagnostic Research : JCDR, 10(3), LC11 -LC14. 2016

17. A'Court C., Stevens R., Sanders S., Ward A., McManus R., Heneghan C. Type And 
Accuracy Of Sphygmomanometers In

Primary Care: A Cross Sectional Observational Study. $\mathrm{Br} J$ Gen Pract. 61(590):e598-603. 2011

18. Gordis, L. Epidemiology, $4^{\text {th }}$ edition. Saunders Elsevier. Philadelphia. 2007.

19. Rahajeng, E dan Tuminah, S. Prevalensi Hipertensi dan Determinannya di Indonesia. Pusat Penelitian Biomedis dan Farmasi Badan Penelitian Kesehatan Departemen Kesehatan RI. Jakarta. 2011

20. Situmorang, P. R. Faktor-Faktor yang Berhubungan dengan Kejadian Hipertensi pada Penderita Rawat Inap di Rumah Sakit Umum Sari Mutiara Medan Tahun 2014. Jurnal Ilmiah Keperawatan , 67-72. 2014.

21. Anggara, F. H., \& Prayitno, N. FaktorFaktor yang Berhubungan dengan Kejadian Tekanan Darah di Puskesmas Telaga Murni, Cikarang Barat. Jurnal Ilmiah Kesehatan , 20-25. 2012. 